\title{
Generalized Contractions of Rational Type in Ordered Partial Metric Spaces
}

\author{
Shujun Jiang ${ }^{1}$ and Zhilong $\mathbf{L i}^{2}$ \\ ${ }^{1}$ Department of Mathematics, Jiangxi University of Finance and Economics, Nanchang 330013, China \\ ${ }^{2}$ School of Statistics, Jiangxi University of Finance and Economics, Nanchang 330013, China \\ Correspondence should be addressed to Zhilong Li; lzl771218@sina.com
}

Received 21 March 2013; Revised 13 October 2013; Accepted 24 October 2013

Academic Editor: Irena Rachůnková

Copyright (c) 2013 S. Jiang and Z. Li. This is an open access article distributed under the Creative Commons Attribution License, which permits unrestricted use, distribution, and reproduction in any medium, provided the original work is properly cited.

\begin{abstract}
Without the continuity and nondecreasing property of the comparison function, we in this paper prove some fixed point theorems of generalized contractions of rational type in ordered partial metric spaces, which generalize and improve the corresponding results of Luong and Thuan. An example is given to support the usability of our results.
\end{abstract}

\section{Introduction and Preliminaries}

Throughout this paper, $\mathbb{R}_{+}$and $\mathbb{N}$ will denote the set of nonnegative real numbers and the set of all positive integer numbers.

It is well known that the Banach contraction principle is one of the pivotal results of analysis. Generalizations of this principle have been obtained in several directions. In [1], Jaggi introduced a contraction of rational type in a metric space and proved the unique existence of fixed point as the contraction is continuous and the metric space is complete, which was then extended to the case of ordered metric spaces by Harjani et al. [2]. In [3], Luong and Thuan considered weak contractions of rational type in ordered metric spaces and proved the following fixed point theorem.

Theorem 1 (see [3]). Let $(X, d, \preceq)$ be a complete ordered metric space and $T: X \rightarrow X$ a nondecreasing mapping such that there exists a function $\eta: \mathbb{R}_{+} \rightarrow \mathbb{R}_{+}$with $\eta^{-1}(\{0\})=\{0\}$ such that

$$
d(T x, T y) \leq M_{d \cdot r}(x, y)-\eta\left(M_{d \cdot r}(x, y)\right),
$$

for all $x, y \in X$ with $x \leq y$ and $x \neq y$, where $M_{d \cdot r}(x, y)=$ $\max \{d(x, y),((d(x, T x) \cdot d(y, T y)) / d(x, y))\}$. Assume that $\eta$ is lower semicontinuous, and $X$ has the following property:

(A1) if $\left\{x_{n}\right\}$ is a nondecreasing sequence in $X$ such that $x_{n} \stackrel{d}{\rightarrow}$ $x$, then $x=\sup \left\{x_{n}\right\}$.
If there exists $x_{0} \in X$ such that $x_{0} \preceq T x_{0}$, then $T$ has a fixed point.

In [4], Matthews introduced the partial metric space and extended the Banach contraction principle to the case of partial metric spaces, which was then improved by Oltra and Valero [5]. In [6-8], the authors studied the unique existence of fixed point of generalized contractions in partial metric spaces. Recall that a mapping $T: X \rightarrow X$ is called a $M_{p^{-}}^{i}$ generalized contraction $\left(M_{p}^{i}\right.$-GC) if there exists a comparison function $\varphi: \mathbb{R}_{+} \rightarrow \mathbb{R}_{+}$such that

$$
p(T x, T y) \leq \varphi\left(M_{p}^{i}(x, y)\right),
$$

where $(X, p)$ is a partial metric space, $M_{p}^{1}(x, y)=$ $\max \{p(x, y), p(x, T x), p(y, T y),(p(x, T y)+p(y, T x)) / 2\}$, and $M_{p}^{2}(x, y)=\max \{p(x, y), p(x, T x), p(y, T y)\}$. Under several different assumptions made on $\varphi$, they obtained the following fixed point results.

Theorem 2 (see Theorem 1 of [6], Theorem 1 of [7], and Theorems 3 and 4 of $[8])$. Let $(X, p)$ be a complete partial metric space. Assume the following.

(i)T:X $\rightarrow X$ is a $M_{p}^{1}$-GC and one of the following conditions is satisfied:

(H1) $\varphi$ is continuous and nondecreasing, and $\varphi(t)<t$ for all $t>0$; 
(H2) $\varphi$ is nondecreasing, and the series $\sum_{n=0}^{\infty} \varphi^{n}(t)$ is convergent for all $t>0\left(\varphi^{n}\right.$ denotes the nth iterate of $\left.\varphi\right)$;

(H3) $\varphi$ is upper semicontinuous from the right, and $\varphi(t)<t$ for all $t>0$.

Or (ii)T:X $\rightarrow X$ is a $M_{p}^{2}$-GC and the following condition is satisfied:

(H4) $\varphi$ is nondecreasing, and $\lim _{n \rightarrow \infty} \varphi^{n}(t)=0$ for all $t>0$. Then $T$ has a unique fixed point.

For other references concerned with various fixed point results and common fixed point results for contractions in the setting of metric-like, partial metric, and ordered partial metric spaces, we refer the readers to [9-24].

In this paper, we establish some fixed point theorems for generalized contractions of rational type in ordered partial metric spaces, which generalize and improve Theorems 1 and 2. An example is given to support the usability of our results. Even in the setting of metric spaces, the results presented in this paper are still new since the comparison function $\varphi$ is not necessarily assumed to be upper semicontinuous from the right or nondecreasing.

Following $[4,5]$, a partial metric on a set $X$ is a function $p: X \times X \rightarrow \mathbb{R}_{+}$such that, for each $x, y, z \in X$,

(p1) $p(x, y)=p(x, x)=p(y, y)$ if and only if $x=y$;

(p2) $p(x, y)=p(y, x)$;

(p3) $p(x, x) \leq p(x, y)$;

(p4) $p(x, y) \leq p(x, z)+p(z, y)-p(z, z)$.

Observe that, if $p(x, y)=0$, then $x=y$. A partial metric space is a pair $(X, p)$ such that $X$ is a set and $p$ is a partial metric on $X$. Each partial metric $p$ on $X$ induces a $T_{0}$ topology $\tau_{p}$ on $X$ which has as a base of the family of open balls $\left\{B_{p}(x, \varepsilon): x \in X, \varepsilon>0\right\}$, where $B_{p}(x, \varepsilon)=\{y \in X: p(x, y)<$ $\varepsilon+p(x, x)\}$ for all $x \in X$ and $\varepsilon>0$.

Let $(X, p)$ be a partial metric space and $\left\{x_{n}\right\}$ a sequence of $X$. The sequence $\left\{x_{n}\right\}$ converges, with respect to $\tau_{p}$, to a point $x \in X$ (denoted by $x_{n} \stackrel{p}{\rightarrow} x$ ) if $\lim _{n \rightarrow \infty} p\left(x_{n}, x\right)=p(x, x)$. Define a function $p^{s}: X \times X \rightarrow \mathbb{R}_{+}$by $p^{s}(x, y)=2 p(x, y)-$ $p(x, x)-p(y, y)$. Then $p^{s}$ is a metric on $X$. The sequence $\left\{x_{n}\right\}$ converges, with respect to $\tau_{p^{s}}$, to a point $x \in X$ (denoted by $\left.x_{n} \stackrel{p^{s}}{\rightarrow} x\right)$ if and only if

$$
\lim _{n \rightarrow \infty} p\left(x_{n}, x\right)=\lim _{m, n \rightarrow \infty} p\left(x_{m}, x_{n}\right)=p(x, x) .
$$

The sequence $\left\{x_{n}\right\}$ is called a Cauchy sequence if $\lim _{m, n \rightarrow \infty} p\left(x_{m}, x_{n}\right)$ exists and is finite; $(X, p)$ is called complete if every Cauchy sequence $\left\{x_{n}\right\} \subset X$ converges, with respect to $\tau_{p}$, to a point $x \in X$ such that $p(x, x)=$ $\lim _{m, n \rightarrow \infty} p\left(x_{m}, x_{n}\right)$. In particular, $\left\{x_{n}\right\}$ is called a 0 -Cauchy sequence if $\lim _{m, n \rightarrow \infty} p\left(x_{m}, x_{n}\right)=0 ;(X, p)$ is called 0 complete if every 0-Cauchy sequence $\left\{x_{n}\right\} \subset X$ converges, with respect to $\tau_{p}$, to a point $x \in X$ such that $p(x, x)=0$. Every complete partial metric space $(X, p)$ is 0 -complete, but the converse may not be true; see [17].

Remark 3 (see $[4,5]$ ). A partial metric space $(X, p)$ is complete if and only if $\left(X, p^{s}\right)$ is complete.

\section{Fixed Point Theorems}

Let $(X, p, \preceq)$ be an ordered partial metric space and $T: X \rightarrow$ $X$. For all $x, y \in X$ with $p(x, y)>0$, set

$$
\begin{aligned}
& M_{p \cdot r}^{1}(x, y)=\max \{ p(x, y), p(x, T x), p(y, T y), \\
&\left.\frac{p(x, T x) \cdot p(y, T y)}{p(x, y)}, \frac{p(x, T y)+p(y, T x)}{2}\right\}, \\
& M_{p \cdot r}^{2}(x, y)=\max \left\{\begin{array}{l}
p(x, y), p(x, T x), p(y, T y), \\
\left.\frac{p(x, T x) \cdot p(y, T y)}{p(x, y)}\right\} .
\end{array}\right.
\end{aligned}
$$

A mapping $T: X \rightarrow X$ is said to be a $M_{p \cdot r}^{i}$-generalized contraction of rational type $\left(M_{p . r}^{i}\right.$-GCRT), if there exists a comparison function $\varphi: \mathbb{R}_{+} \rightarrow \mathbb{R}_{+}$such that

$$
p(T x, T y) \leq \varphi\left(M_{p . r}^{i}(x, y)\right)
$$

for all $x, y \in X$ with $x \preceq y$ and $p(x, y)>0$.

Lemma 4. Let $(X, p, \preceq)$ be an ordered partial metric space and $T: X \rightarrow X$ a nondecreasing $M_{p . r}^{1}$-GCRT. Assume that

(H5) $\varphi(s)<s$ and $\lim \sup _{t \rightarrow s^{+}}(\varphi(t) / t)<1$ for all $s>0$.

For each $x_{0} \in X$ such that $x_{0} \preceq T x_{0}$, let $x_{n}=T^{n} x_{0}$ for all $n \in \mathbb{N}$. If $x_{n} \neq x_{n-1}$ for all $n \in \mathbb{N}$, then

$$
\lim _{m, n \rightarrow \infty} p\left(x_{m}, x_{n}\right)=0
$$

Proof. Note that $T$ is nondecreasing and $x_{0} \preceq T x_{0}$; then $\left\{x_{n}\right\}$ is nondecreasing. Since $x_{n} \neq x_{n-1}$ for all $n \in \mathbb{N}$, then

$$
p\left(x_{n-1}, x_{n}\right)>0
$$

for all $n \in \mathbb{N}$. By (4) and (p4), for all $n \in \mathbb{N}$, we have

$$
\begin{aligned}
\max & \left\{p\left(x_{n-1}, x_{n}\right), p\left(x_{n}, x_{n+1}\right)\right\} \\
& \leq \max \left\{p\left(x_{n-1}, x_{n}\right), p\left(x_{n}, x_{n+1}\right), \frac{p\left(x_{n-1}, x_{n+1}\right)+p\left(x_{n}, x_{n}\right)}{2}\right\} \\
& =M_{p \cdot r}^{1}\left(x_{n-1}, x_{n}\right) \\
& \leq \max \left\{p\left(x_{n-1}, x_{n}\right), p\left(x_{n}, x_{n+1}\right), \frac{p\left(x_{n-1}, x_{n}\right)+p\left(x_{n}, x_{n+1}\right)}{2}\right\} \\
& =\max \left\{p\left(x_{n-1}, x_{n}\right), p\left(x_{n}, x_{n+1}\right)\right\} .
\end{aligned}
$$

Thus by the nondecreasing property of $\left\{x_{n}\right\},(7)$, and (8),

$$
\begin{aligned}
p\left(x_{n}, x_{n+1}\right) & \leq \varphi\left(M_{p \cdot r}^{1}\left(x_{n-1}, x_{n}\right)\right) \\
& =\varphi\left(\max \left\{p\left(x_{n-1}, x_{n}\right), p\left(x_{n}, x_{n+1}\right)\right\}\right),
\end{aligned}
$$


for all $n \in \mathbb{N}$. Now, we claim that, for all $n \in \mathbb{N}$,

$$
p\left(x_{n}, x_{n+1}\right) \leq p\left(x_{n-1}, x_{n}\right) .
$$

Suppose, on the contrary, that there exists some $n \in \mathbb{N}$ such that $p\left(x_{n}, x_{n+1}\right)>p\left(x_{n-1}, x_{n}\right)$. Then by (8), (9), and $\varphi(s)<s$ for all $s>0$, we have

$$
p\left(x_{n}, x_{n+1}\right) \leq \varphi\left(p\left(x_{n}, x_{n+1}\right)\right)<p\left(x_{n}, x_{n+1}\right) .
$$

This is a contradiction and hence (10) is true. Consequently, $\left\{p\left(x_{n}, x_{n+1}\right)\right\}$ is a decreasing sequence of positive real numbers. This yields that there exists $\alpha \geq 0$ such that

$$
p\left(x_{n}, x_{n+1}\right) \longrightarrow \alpha^{+} \text {. }
$$

In the following, we will show that $\alpha=0$. Suppose, on the contrary, that $\alpha>0$. It follows from (8), (9), and (10) that, for all $n \in \mathbb{N}$,

$$
\frac{p\left(x_{n}, x_{n+1}\right)}{p\left(x_{n-1}, x_{n}\right)} \leq \frac{\varphi\left(p\left(x_{n-1}, x_{n}\right)\right)}{p\left(x_{n-1}, x_{n}\right)} \text {. }
$$

Letting $n \rightarrow \infty$ in (13), by (12), (H5), and $\alpha>0$, we get a contradiction $1 \leq \limsup _{t \rightarrow \alpha^{+}}(\varphi(t) / t)<1$. Hence $\alpha=0$, and consequently by (12)

$$
\lim _{n \rightarrow \infty} p\left(x_{n}, x_{n+1}\right)=0 .
$$

Now, we show that conclusion (6) is true. If otherwise, there exist some $\beta>0$ and subsequences $\left\{m_{k}\right\}_{k \in \mathbb{N}}$ and $\left\{n_{k}\right\}_{k \in \mathbb{N}}$ in $\mathbb{N}$, with $m_{k}>n_{k} \geq k$, such that, for all $k \in \mathbb{N}$,

$$
p\left(x_{n_{k}}, x_{m_{k}}\right) \geq \beta \text {. }
$$

From (15) we may assume that, without loss of generality, for all $k \in \mathbb{N}$,

$$
p\left(x_{n_{k}}, x_{m_{k}-1}\right)<\beta .
$$

Then by (p4), for all $k \in \mathbb{N}$, we have

$$
\begin{aligned}
\beta & \leq p\left(x_{n_{k}}, x_{m_{k}}\right) \leq p\left(x_{n_{k}}, x_{m_{k}-1}\right)+p\left(x_{m_{k}}, x_{m_{k}-1}\right) \\
& <\beta+p\left(x_{m_{k}}, x_{m_{k}-1}\right) .
\end{aligned}
$$

Letting $k \rightarrow \infty$ in the above inequality, by (14), we get

$$
\lim _{k \rightarrow \infty} p\left(x_{n_{k}}, x_{m_{k}}\right)=\beta
$$

Also by (p4), for all $k \in \mathbb{N}$, we have

$$
\begin{aligned}
& p\left(x_{n_{k}}, x_{m_{k}}\right)-p\left(x_{n_{k}}, x_{n_{k}+1}\right)-p\left(x_{m_{k}}, x_{m_{k}+1}\right) \\
& \quad \leq p\left(x_{n_{k}+1}, x_{m_{k}+1}\right) \\
& \quad \leq p\left(x_{n_{k}}, x_{n_{k}+1}\right)+p\left(x_{n_{k}}, x_{m_{k}}\right)+p\left(x_{m_{k}}, x_{m_{k}+1}\right) .
\end{aligned}
$$

Letting $k \rightarrow \infty$ in the above inequality, by (14) and (18), we get

$$
\lim _{k \rightarrow \infty} p\left(x_{n_{k}+1}, x_{m_{k}+1}\right)=\beta
$$

Similarly, we can obtain

$$
\lim _{k \rightarrow \infty} p\left(x_{n_{k}}, x_{m_{k}+1}\right)=\lim _{k \rightarrow \infty} p\left(x_{n_{k}+1}, x_{m_{k}}\right)=\beta .
$$

By the nondecreasing property of $\left\{x_{n}\right\},(5)$, and (15), we get, for all $k \in \mathbb{N}$,

$$
p\left(x_{n_{k}+1}, x_{m_{k}+1}\right)=p\left(T x_{n_{k}}, T x_{m_{k}}\right) \leq \varphi\left(M_{p . r}^{1}\left(x_{n_{k}}, x_{m_{k}}\right)\right),
$$

where $M_{p . r}^{1}\left(x_{n_{k}}, x_{m_{k}}\right)=\max \left\{p\left(x_{n_{k}}, x_{m_{k}}\right), p\left(x_{n_{k}}, x_{n_{k}+1}\right)\right.$, $p\left(x_{m_{k}}, x_{m_{k}+1}\right),\left(p\left(\left(x_{n_{k}}, x_{n_{k}+1}\right) \cdot p\left(x_{m_{k}}, x_{m_{k}+1}\right)\right) / p\left(x_{n_{k}}, x_{m_{k}}\right)\right)$, $\left.\left(p\left(x_{n_{k}}, x_{m_{k}+1}\right)+p\left(x_{n_{k}+1}, x_{m_{k}}\right) / 2\right)\right\}$. By (14) and (18), we have

$$
\lim _{k \rightarrow \infty} \frac{p\left(x_{n_{k}}, x_{n_{k}+1}\right) \cdot p\left(x_{m_{k}}, x_{m_{k}+1}\right)}{p\left(x_{n_{k}}, x_{m_{k}}\right)}=0,
$$

which together with (14), (18), and (21) implies that there exists $k_{1} \in \mathbb{N}$ such that, for all $k \geq k_{1}$,

$$
M_{p \cdot r}^{1}\left(x_{n_{k}}, x_{m_{k}}\right)=M_{1}\left(x_{n_{k}}, x_{m_{k}}\right),
$$

where $M_{1}\left(x_{n_{k}}, x_{m_{k}}\right)=\max \left\{p\left(x_{n_{k}}, x_{m_{k}}\right),\left(p\left(x_{n_{k}}, x_{m_{k}+1}\right)+\right.\right.$ $\left.\left.p\left(x_{n_{k}+1}, x_{m_{k}}\right)\right) / 2\right\}$. It follows from (15), (18), and (21) that

$$
M_{1}\left(x_{n_{k}}, x_{m_{k}}\right) \longrightarrow \beta^{+},
$$

By (15), (22), and (24), we have, for all $k \geq k_{1}$,

$$
\frac{p\left(x_{n_{k}+1}, x_{m_{k}+1}\right)}{M_{1}\left(x_{n_{k}}, x_{m_{k}}\right)} \leq \frac{\varphi\left(M_{1}\left(x_{n_{k}}, x_{m_{k}}\right)\right)}{M_{1}\left(x_{n_{k}}, x_{m_{k}}\right)} .
$$

Letting $k \rightarrow \infty$ in (26), by (20), (25), (H5), and $\beta>0$, we get a contradiction $1 \leq \limsup _{t \rightarrow \beta^{+}}(\varphi(t) / t)<1$. Hence conclusion (6) is true. The proof is complete.

Remark 5. It is easy to see that Lemma 4 is still valid for $M_{p \cdot r^{-}}^{2}$ GCRT and $M_{p}^{1}$-GC.

Theorem 6. Let $(X, p, \preceq)$ be a 0 -complete ordered partial metric space and $T: X \rightarrow X$ a nondecreasing $M_{p \cdot r}^{1}-G C R T$. Assume that

(H6) $\varphi(s)<s$ and $\lim \sup _{t \rightarrow s}(\varphi(t) / t)<1$, for all $s>0$, and $X$ has the following property:

(A2) if $\left\{x_{n}\right\}$ is a nondecreasing sequence in $X$ such that $x_{n} \stackrel{p^{s}}{\rightarrow} x$, then $x=\sup \left\{x_{n}\right\}$.

If there exists $x_{0} \in X$ such that $x_{0} \preceq T x_{0}$, then $T$ has a fixed point.

Proof. Let $x_{n}=T^{n} x_{0}$ for all $n \in \mathbb{N}$. If there exists some $n \in \mathbb{N}$ such that $T x_{n-1}=x_{n}=x_{n-1}$, then $x_{n-1}$ is a fixed point and hence the proof is complete. Therefore, we may assume that $x_{n} \neq x_{n-1}$ for all $n \in \mathbb{N}$. By Lemma $4,\left\{x_{n}\right\}$ is 0 -Cauchy. So by the 0 -completeness of $X$, there exists $x_{*} \in X$ such that $x_{n} \stackrel{p}{\rightarrow} x_{*}$, and consider

$$
\lim _{n \rightarrow \infty} p\left(x_{n}, x_{*}\right)=p\left(x_{*}, x_{*}\right)=\lim _{m, n \rightarrow \infty} p\left(x_{m}, x_{n}\right)=0 .
$$


That is, $x_{n} \stackrel{p^{s}}{\rightarrow} x_{*}$. By (A2), $\sup \left\{x_{n}\right\}=x^{*}$, and so, for all $n \in \mathbb{N}$,

$$
x_{n} \preceq x_{*} .
$$

Now, we claim that, for all $n \in \mathbb{N}$,

$$
x_{n} \neq x_{*} .
$$

If otherwise, there exists some $n_{*}$ such that $x_{n_{*}}=x_{*}$; then $x_{n}=x_{*}$ for all $n \geq n_{*}$ since $\left\{x_{n}\right\}$ is nondecreasing. This contradicts with the assumption $x_{n} \neq x_{n-1}$ for all $n \in \mathbb{N}$, and hence (29) is true. Since $T$ is nondecreasing, then $x_{n+1}=$ $T x_{n} \preceq T x_{*}$, for all $n \in \mathbb{N}$, and hence by (A2)

$$
x_{*}=\sup \left\{x_{n}\right\} \preceq T x_{*} .
$$

Let $y_{n}=T^{n} x_{*}$ for all $n \in \mathbb{N}$. Then $\left\{y_{n}\right\}$ is a nondecreasing sequence since $T$ is nondecreasing. We may assume that, for all $n \in \mathbb{N}$,

$$
y_{n} \neq y_{n-1}
$$

If otherwise, there exists some $n \in \mathbb{N}$ such that $T y_{n-1}=$ $y_{n}=y_{n-1}$; then $y_{n-1}$ is a fixed point and hence the proof is complete. By Lemma 4 and the 0 -completeness of $X$, there exists $y_{*} \in X$ such that $y_{n} \stackrel{p}{\rightarrow} y_{*}$, and consider

$$
\lim _{n \rightarrow \infty} p\left(y_{n}, y_{*}\right)=p\left(y_{*}, y_{*}\right)=\lim _{m, n \rightarrow \infty} p\left(y_{m}, y_{n}\right)=0 \text {. }
$$

That is, $y_{n} \stackrel{p^{s}}{\rightarrow} y_{*}$. By (A2), we have, for all $n \in \mathbb{N}$,

$$
y_{n} \preceq y_{*} .
$$

It follows from $x_{n} \stackrel{p^{s}}{\rightarrow} x_{*}, y_{n} \stackrel{p^{s}}{\rightarrow} y_{*}$, and the continuity of the metric $p^{s}$ that

$$
\lim _{n \rightarrow \infty} p^{s}\left(x_{n}, y_{n}\right)=p^{s}\left(x_{*}, y_{*}\right)
$$

That is,

$$
\lim _{n \rightarrow \infty}\left[2 p\left(x_{n}, y_{n}\right)-p\left(x_{n}, x_{n}\right)-p\left(y_{n}, y_{n}\right)\right]=2 p\left(x_{*}, y_{*}\right),
$$

which together with (27) and (32) implies that

$$
\lim _{n \rightarrow \infty} p\left(x_{n}, y_{n}\right)=p\left(x_{*}, y_{*}\right)
$$

By (p4), we have, $n \in \mathbb{N}$,

$$
\begin{aligned}
& p\left(x_{n}, y_{n}\right)-p\left(x_{n}, x_{n+1}\right) \\
& \quad \leq p\left(x_{n+1}, y_{n}\right) \leq p\left(x_{n}, y_{n}\right)+p\left(x_{n}, x_{n+1}\right), \\
& p\left(x_{n}, y_{n}\right)-p\left(y_{n}, y_{n+1}\right) \\
& \quad \leq p\left(x_{n}, y_{n+1}\right) \leq p\left(x_{n}, y_{n}\right)+p\left(y_{n}, y_{n+1}\right) .
\end{aligned}
$$

Letting $n \rightarrow \infty$ in the above two inequalities, by (27), (32), and (36), we get

$$
\lim _{n \rightarrow \infty} p\left(x_{n+1}, y_{n}\right)=\lim _{n \rightarrow \infty} p\left(x_{n}, y_{n+1}\right)=p\left(x_{*}, y_{*}\right) \text {. }
$$

In what follows, we will show $x_{*}=y_{*}$. Suppose, on the contrary, that $x_{*} \neq y_{*}$; then $p\left(x_{*}, y_{*}\right)>0$. Clearly, $x_{n} \preceq y_{n}$ and $x_{n} \neq y_{n}$ for all $n \in \mathbb{N}$ by (29), (30), and (31). Consequently,

$$
p\left(x_{n}, y_{n}\right)>0,
$$

for all $n \in \mathbb{N}$. Thus by (5), we have, for all $n \in \mathbb{N}$,

$$
p\left(x_{n+1}, y_{n+1}\right)=p\left(T x_{n}, T y_{n}\right) \leq \varphi\left(M_{p . r}^{1}\left(x_{n}, y_{n}\right)\right)
$$

where $M_{p \cdot r}^{1}\left(x_{n}, y_{n}\right)=\max \left\{p\left(x_{n}, y_{n}\right), p\left(x_{n}, x_{n+1}\right), p\left(y_{n}, y_{n+1}\right)\right.$, $\left(p\left(x_{n}, x_{n+1}\right) \cdot p\left(y_{n}, y_{n+1}\right)\right) / p\left(x_{n}, y_{n}\right),\left(p\left(x_{n}, y_{n+1}\right)+p\left(y_{n}\right.\right.$, $\left.\left.x_{n+1}\right)\right) / 2$ \}. By (27), (32), and (36), we have

$$
\lim _{n \rightarrow \infty} \frac{p\left(x_{n}, x_{n+1}\right) \cdot p\left(y_{n}, y_{n+1}\right)}{p\left(x_{n}, y_{n}\right)}=0,
$$

which together with (27), (32), (36), and (38) implies that there exists $n_{1} \in \mathbb{N}$ such that, for all $n \geq n_{1}$,

$$
M_{p . r}^{1}\left(x_{n}, y_{n}\right)=M_{2}\left(x_{n}, y_{n}\right)
$$

where $M_{2}\left(x_{n}, y_{n}\right)=\max \left\{p\left(x_{n}, y_{n}\right),\left(p\left(x_{n}, y_{n+1}\right)+p\left(y_{n}\right.\right.\right.$, $\left.\left.\left.x_{n+1}\right)\right) / 2\right\}$. It follows from (36) and (38) that

$$
M_{2}\left(x_{n}, y_{n}\right) \longrightarrow p\left(x_{*}, y_{*}\right) \text {. }
$$

By (39), (40), and (42), we have, for all $n \geq n_{1}$,

$$
\frac{p\left(x_{n+1}, y_{n+1}\right)}{M_{2}\left(x_{n}, y_{n}\right)} \leq \frac{\varphi\left(M_{2}\left(x_{n}, y_{n}\right)\right)}{M_{2}\left(x_{n}, y_{n}\right)} .
$$

Letting $n \rightarrow \infty$ in (44), by (36), (43), (H6), and $p\left(x_{*}, y_{*}\right)>$ 0 , we get a contradiction $1 \leq \limsup _{t \rightarrow p\left(x_{*}, y_{*}\right)}(\varphi(t) / t)<1$. Hence $p\left(x_{*}, y_{*}\right)=0$, and consequently $x_{*}=y_{*}$. From (30) and (33), it follows that $x_{*} \preceq T x_{*}=y_{1} \preceq y_{*}$. This together with $x_{*}=y_{*}$ yields that $x_{*}=T x_{*}$. The proof is complete.

In particular when $T$ is a $M_{p \cdot r}^{2}$-GCRT, condition (H6) could be weakened, and we have the following result.

Theorem 7. Let $(X, p, \preceq)$ be a 0 -complete ordered partial metric space and $T: X \rightarrow X$ a nondecreasing $M_{p \cdot r}^{2}-G C R T$. Assume that (H5) is satisfied and $X$ has property (A2). If there exists $x_{0} \in X$ such that $x_{0} \preceq T x_{0}$, then $T$ has a fixed point.

Proof. Following the proof of Theorem 6, we find that (27)(36) and (39) still hold by Remark 5. Instead of (40), by (5), (6), (39), and $x_{n} \preceq y_{n}$, we have, for all $n \in \mathbb{N}$,

$$
\begin{aligned}
p\left(x_{n+1}, y_{n+1}\right) & =p\left(T x_{n}, T y_{n}\right) \\
& \leq \varphi\left(M_{p . r}^{2}\left(x_{n}, y_{n}\right)\right)<M_{p . r}^{2}\left(x_{n}, y_{n}\right),
\end{aligned}
$$

where $M_{p \cdot r}^{2}\left(x_{n}, y_{n}\right)=\max \left\{p\left(x_{n}, y_{n}\right), p\left(x_{n}, x_{n+1}\right), p\left(y_{n}, y_{n+1}\right)\right.$, $\left.\left(p\left(x_{n}, x_{n+1}\right) \cdot p\left(y_{n}, y_{n+1}\right)\right) / p\left(x_{n}, y_{n}\right)\right\}$. By (28), (32), (36), and $p\left(x_{*}, y_{*}\right)>0$, there exists $n_{2} \in \mathbb{N}$ such that, for all $n \geq n_{2}$,

$$
M_{p . r}^{2}\left(x_{n}, \mathrm{y}_{n}\right)=p\left(x_{n}, y_{n}\right) \text {, }
$$


which together with (45) implies that, for all $n \geq n_{2}$,

$$
p\left(x_{n+1}, y_{n+1}\right)<p\left(x_{n}, y_{n}\right) \text {. }
$$

That is, $\left\{p\left(x_{n}, y_{n}\right)\right\}_{n=n_{2}}^{\infty}$ is decreasing. Moreover by (36), we have

$$
p\left(x_{n}, y_{n}\right) \longrightarrow p\left(x_{*}, y_{*}\right)^{+}
$$

Instead of (44), by (39), (45), and (46), for all $n \geq n_{2}$,

$$
\frac{p\left(x_{n+1}, y_{n+1}\right)}{p\left(x_{n}, y_{n}\right)} \leq \frac{\varphi\left(p\left(x_{n}, y_{n}\right)\right)}{p\left(x_{n}, y_{n}\right)} \text {. }
$$

Letting $n \rightarrow \infty$ in (49), by (48), (H5), and $p\left(x_{*}, y_{*}\right)>0$, we get a contradiction $1 \leq \lim _{t \rightarrow p\left(x_{*}, y_{*}\right)^{+}}(\varphi(t) / t)<1$. Hence $p\left(x_{*}, y_{*}\right)=0$, and consequently $x_{*}=y_{*}$. From (30) and (33), it follows that $x_{*} \preceq T x_{*}=y_{1} \preceq y_{*}$. This together with $x_{*}=y_{*}$ yields that $x_{*}=T x_{*}$. The proof is complete.

Corollary 8. Let $(X, p, \preceq)$ be a 0-complete ordered partial metric space and $T: X \rightarrow X$ a nondecreasing mapping such that there exists a function $\eta: \mathbb{R}_{+} \rightarrow \mathbb{R}_{+}$with $\eta^{-1}(\{0\})=\{0\}$ such that

$$
p(T x, T y) \leq M_{p \cdot r}^{2}(x, y)-\eta\left(M_{p \cdot r}^{2}(x, y)\right),
$$

for all $x, y \in X$ with $x \preceq y$ and $p(x, y)>0$. Assume that, for all $s>0$,

$$
\liminf _{t \rightarrow s^{+}} \frac{\eta(t)}{t}>0
$$

and $X$ has property (A2). If there exists $x_{0} \in X$ such that $x_{0} \preceq$ $T x_{0}$, then $T$ has a fixed point.

Proof. Let $\varphi(t)=t-\eta(t)$. Clearly, $\varphi(t)<t$ for all $t>0$ by $\eta^{-1}(\{0\})=\{0\}$. For all $s>0$, it follows from (51) that

$$
\limsup _{t \rightarrow s^{+}} \frac{\varphi(t)}{t}=\limsup _{t \rightarrow s^{+}} \frac{t-\eta(t)}{t} \leq 1-\liminf _{t \rightarrow s^{+}} \frac{\eta(t)}{t}<1 .
$$

Then the conclusion follows immediately from Theorem 7. The proof is complete.

Remark 9. If $\eta$ is lower semicontinuous from the right and $\eta^{-1}(\{0\})=\{0\}$, then, for all $s>0$,

$$
\liminf _{t \rightarrow s^{+}} \frac{\eta(t)}{t} \geq \frac{\eta(s)}{s}>0 .
$$

Therefore Theorem 1 follows immediately from Corollary 8 .

Now we illustrate Theorems 6 and 7 by the following example.

Example 10. Let $X=\mathbb{R}_{+}$with the partial metric $p(x, y)=$ $\max \{x, y\}$ for all $x, y \in X$. Clearly, $p^{s}(x, y)=2 p(x, y)-$ $p(x, x)-p(y, y)=|x-y|$ and hence, by Remark 3, $(X, p)$ is a complete partial metric space since $\left(X, p^{s}\right)$ is a complete metric space. Define a partial order $\preceq$ on $X$ by

$$
x \preceq y \Longleftrightarrow \begin{cases}x=y, & x, y \in X \backslash(\{0\} \cup B), \\ x \leq y, & x, y \in\{0\} \cup B,\end{cases}
$$

where $B=\{(1 / n): n=2,3, \ldots\}$ and $\leq$ is the usual order of reals. Let

$$
\begin{aligned}
& T x= \begin{cases}0, & x=X \backslash B, \\
\frac{x}{1+x}, & x=\frac{1}{n}, n=2,4, \ldots,\end{cases} \\
& \varphi(t)= \begin{cases}t-t^{3}, & t \in[0,1) \backslash B, \\
\frac{t}{1+t}, & t=\frac{1}{n}, n=2,3, \ldots, \\
t-\frac{1}{2}, & t \geq 1\end{cases}
\end{aligned}
$$

It is easy to see that $T$ is nondecreasing, $X$ has property (A2), and $\varphi(t)<t$ for all $t>0$. Direct calculations give that

$$
\limsup _{t \rightarrow s} \frac{\varphi(t)}{t}=\left\{\begin{array}{l}
1-s^{2}<1, \quad s \in(0,1), \\
1-\frac{1}{2 s}<1, \quad s \geq 1
\end{array}\right.
$$

That is, (H6) is satisfied. In particular, (H5) is satisfied. For each $x, y \in X \backslash B$ with $x \preceq y$ and $p(x, y)>0$, we must have $p(T x, T y)=0$ and hence $p(T x, T y) \leq \varphi\left(M_{p . r}^{i}(x, y)\right), i=1,2$. For each $x, y \in\{0\} \cup B$ with $x \preceq y$ and $p(x, y)>0$, we have two cases:

(i) if $x=0$ and $y=(1 / n), n \geq 2$, then $p(T x, T y)=$ $1 /(n+1) \leq 1 / n=p(x, y)=M_{p . r}^{i}(x, y), i=1,2 ;$

(ii) if $y=1 / n$ and $x=1 / m, m \geq n \geq 3$, then $p(T x, T y)=$ $1 /(n+1) \leq 1 / n=p(x, y)=M_{p . r}^{i}(x, y), i=1,2$.

Thus by (56), $p(T x, T y) \leq M_{p . r}^{i}(x, y)=$ $\varphi\left(M_{p \cdot r}^{i}(x, y)\right), i=1,2$. This shows that $T$ is a $M_{p \cdot r^{-}}^{i}$ $\operatorname{GCRT}(i=1,2)$, and consequently the existence of fixed point follows immediately from Theorem 6 or Theorem 7 . In fact, 0 is a fixed point of $T$.

In what follows, we will extend Theorem 2 to the case of ordered partial metric space under weaker conditions.

Theorem 11. Let $(X, p, \preceq)$ be a 0-complete ordered partial metric space and $T: X \rightarrow X$ a nondecreasing mapping such that, for each $x, y \in X$ with $x \preceq y$, (2) is satisfied for $M_{p}^{1}$. Assume that either (H4) or (H5) is satisfied and X has the following property:

(A3) if $\left\{x_{n}\right\}$ is a nondecreasing sequence in $X$ such that $x_{n} \stackrel{p^{s}}{\rightarrow} x$, then $x_{n} \preceq x$ for all $n \in \mathbb{N}$.

If there exists $x_{0} \in X$ such that $x_{0} \preceq T x_{0}$, then $T$ has a fixed point. 
Proof.

Case 1 ((H5) is satisfied). Following the proof of Theorem 6, we get (27) and (28) by Remark 5 and (A3). By (p4), for all $n \in \mathbb{N}$,

$$
\begin{aligned}
& p\left(x_{*}, T x_{*}\right)-p\left(x_{n+1}, x_{*}\right) \leq p\left(x_{n+1}, T x_{*}\right) \\
& \quad \leq p\left(x_{*}, T x_{*}\right)+p\left(x_{n+1}, x_{*}\right) .
\end{aligned}
$$

Letting $n \rightarrow \infty$ in (58), by (27), we get

$$
\lim _{n \rightarrow \infty} p\left(x_{n+1}, T x_{*}\right)=p\left(x_{*}, T x_{*}\right) \text {. }
$$

Now, we show that $x_{*}$ is a fixed point of $T$. If otherwise, then $p\left(x_{*}, T x_{*}\right)>0$. By $(\mathrm{p} 4),(2)$, and (28), we have, for all $n \in \mathbb{N}$,

$$
\begin{aligned}
p\left(x_{*}, T x_{*}\right) & \leq p\left(x_{n+1}, x_{*}\right)+p\left(T x_{n}, T x_{*}\right) \\
& \leq p\left(x_{n+1}, x_{*}\right)+\varphi\left(M_{p}^{1}\left(x_{n}, x_{*}\right)\right),
\end{aligned}
$$

where $M_{p}^{1}\left(x_{n}, x_{*}\right)=\max \left\{p\left(x_{n}, x_{*}\right), p\left(x_{n}, x_{n+1}\right), p\left(x_{*}, T x_{*}\right)\right.$, $\left.\left(p\left(x_{n}, T x_{*}\right)+p\left(x_{*}, x_{n+1}\right)\right) / 2\right\}$. It follows from (27) and (59) that

$$
\lim _{n \rightarrow \infty} \frac{p\left(x_{n}, T x_{*}\right)+p\left(x_{*}, x_{n+1}\right)}{2}=\frac{p\left(x_{*}, T x_{*}\right)}{2},
$$

which together with (27) implies that there exist $\delta_{0} \epsilon$ $\left(0, p\left(x_{*}, T x_{*}\right) / 2\right]$ and $n_{0} \in \mathbb{N}$ such that, for all $n \geq n_{0}$,

$$
\begin{aligned}
\frac{p\left(x_{n}, T x_{*}\right)+p\left(x_{*}, x_{n+1}\right)}{2} & \leq \frac{p\left(x_{*}, T x_{*}\right)}{2}+\delta_{0} \leq p\left(x_{*}, T x_{*}\right), \\
p\left(x_{n}, x_{*}\right) & \leq \delta_{0}, \quad p\left(x_{n}, x_{n+1}\right) \leq \delta_{0} .
\end{aligned}
$$

Thus, for all $n \geq n_{0}$,

$$
M_{p}^{1}\left(x_{n}, x_{*}\right)=p\left(x_{*}, T x_{*}\right),
$$

and hence, by (60),

$$
p\left(x_{*}, T x_{*}\right) \leq p\left(x_{n+1}, x_{*}\right)+\varphi\left(p\left(x_{*}, T x_{*}\right)\right) .
$$

Letting $n \rightarrow \infty$ in (64), by (27), we get a contradiction

$$
p\left(x_{*}, T x_{*}\right) \leq \varphi\left(p\left(x_{*}, T x_{*}\right)\right)<p\left(x_{*}, T x_{*}\right),
$$

since $\varphi(s)<s$ for all $s>0$. Hence $x_{*}$ is a fixed point of $T$.

Case 2 ((H4) is satisfied). By the same method used in Lemma 4 and [8, Theorem 4], we can show that (27) and (59) still hold. Then by analogy to Case $1, x_{*}$ is a fixed point of $T$. The proof is complete.

Remark 12. If $T$ is a generalized contraction of rational type, then the method used in Theorem 11 fails to work since there exists $n_{0} \in \mathbb{N}$ such that $M_{p . r}^{i}\left(x_{n}, x_{*}\right)=p\left(x_{*}, T x_{*}\right)$ for all $n \geq$ $n_{0}$ unless $\lim _{n \rightarrow \infty} p\left(x_{n}, x_{n+1}\right) / p\left(x_{n}, x_{*}\right) \leq 1$, which could not be done. Therefore the existence of fixed point of generalized contractions of rational type could not be obtained under the weaker condition (A3).
By the methods used in Theorem 11 and [8, Theorem 4], we have the following fixed point result.

Theorem 13. Let $(X, p)$ be a 0 -complete partial metric space and $T: X \rightarrow X$ a $M_{p}^{1}$-GC. If either (H4) or (H5) is satisfied, then $T$ has a unique fixed point.

Remark 14. (i) In the case that (H5) is satisfied, the continuity and nondecreasing property of $\varphi$ necessarily assumed in Theorem 2 is removed in Theorem 13. Note that (H3) implies (H5); then Theorem 13 improves Theorem 1 of [6], Theorem 3 of [8], and Theorem 2.3 of [23].

(ii) In the case that $(\mathrm{H} 4)$ is satisfied, Theorem 13 is generalization of Theorem 4 of [8] to the case of $M_{p}^{1}$-GC and hence improves Theorem 1 of [7] since (H2) implies (H4).

Example 15. Let $X=\{0\} \cup\{1 / n: n=2,3, \ldots\}$ with the partial metric $p(x, y)=\max \{x, y\}$ for all $x, y \in X$. By analogy to Example 10, we find from Remark 3 that $(X, p)$ is a complete partial metric space. Let

$$
T x= \begin{cases}0, & x=0, \\ \frac{x}{1+x}, & x=\frac{1}{n}, n=2,3, \ldots,\end{cases}
$$

and $\varphi$ is given by (56). It is easy to check that $T$ is a $M_{p}^{1}-\mathrm{GC}$ and (H5) is satisfied. Therefore the unique existence of fixed point follows immediately from Theorem 13. In fact, 0 is the unique fixed point of $T$.

For each $s=1 / n, n \geq 2$, we have $\limsup _{t \rightarrow s^{+}} \varphi(t)=\left(n^{2}-\right.$ $1) / n^{3}>1 /(n+1)=\varphi(s)$. This implies that $\varphi$ is not upper semicontinuous from the right at $s=1 / n, n \geq 2$. Meanwhile, it is clear that $\varphi$ is decreasing on $(1 / 3,1)$. Therefore, we cannot invoke Theorem 2 to show the unique existence of fixed point.

Remark 16. It is worth mentioning that, even in the setting of metric spaces, the main results in this paper are still new since the continuity and nondecreasing property of the comparison function $\varphi$ necessarily assumed in [24] and other relating references is removed.

\section{Acknowledgments}

This work was supported by the Natural Science Foundation of China (11161022), the Natural Science Foundation of Jiangxi Province (20114BAB211006, 20122BAB201015), the Educational Department of Jiangxi Province (GJJ12280, GJJ13297), and the Program for Excellent Youth Talents of JXUFE (201201).

\section{References}

[1] D. S. Jaggi, "Some unique fixed point theorems," Indian Journal of Pure and Applied Mathematics, vol. 8, no. 2, pp. 223-230, 1977.

[2] J. Harjani, B. López, and K. Sadarangani, "A fixed point theorem for mappings satisfying a contractive condition of rational type on a partially ordered metric space," Abstract and Applied Analysis, vol. 2010, Article ID 190701, 8 pages, 2010.

[3] N. V. Luong and N. X. Thuan, "Fixed point theorem for generalized weak contractions satisfying rational expressions in 
ordered metric spaces," Fixed Point Theory and Applications, vol. 2011, article 46, 2011.

[4] S. G. Matthews, "Partial metric topology," Annals of the New York Academy of Sciences, vol. 728, pp. 183-197, 1994, Proceedings of the 8th Summer Conference on General Topology and Applications.

[5] S. Oltra and O. Valero, "Banach's fixed point theorem for partial metric spaces," Rendiconti dell'Istituto di Matematica dell'Università di Trieste, vol. 36, no. 1-2, pp. 17-26, 2004.

[6] I. Altun, F. Sola, and H. Simsek, "Generalized contractions on partial metric spaces," Topology and Its Applications, vol. 157, no. 18, pp. 2778-2785, 2010.

[7] I. Altun and K. Sadarangani, "Corrigendum to "Generalized contractions on partial metric spaces" [Topology Appl. 157 (2010) 2778-2785]," Topology and Its Applications, vol. 158, no. 13, pp. 1738-1740, 2011.

[8] S. Romaguera, "Fixed point theorems for generalized contractions on partial metric spaces," Topology and Its Applications, vol. 159, no. 1, pp. 194-199, 2012.

[9] A. Amini-Harandi, "Metric-like spaces, partial metric spaces and fixed points," Fixed Point Theory and Applications, vol. 2012, article 204, 2012.

[10] M. Bukatin, R. Kopperman, S. Matthews, and H. Pajoohesh, "Partial metric spaces," American Mathematical Monthly, vol. 116, no. 8, pp. 708-718, 2009.

[11] E. Karapinar and I. M. Erhan, "Fixed point theorems for operators on partial metric spaces," Applied Mathematics Letters, vol. 24, no. 11, pp. 1894-1899, 2011.

[12] S. Romaguera, "A Kirk type characterization of completeness for partial metric spaces," Fixed Point Theory and Applications, vol. 2010, Article ID 493298, 6 pages, 2010.

[13] D. Ilić, V. Pavlović, and V. Rakočević, "Some new extensions of Banach's contraction principle to partial metric space," Applied Mathematics Letters, vol. 24, no. 8, pp. 1326-1330, 2011.

[14] L. Ćirić, B. Samet, H. Aydi, and C. Vetro, "Common fixed points of generalized contractions on partial metric spaces and an application," Applied Mathematics and Computation, vol. 218, no. 6, pp. 2398-2406, 2011.

[15] B. Samet, M. Rajović, R. Lazović, and R. Stojiljković, "Common fixed point results for nonlinear contractions in ordered partial metric spaces," Fixed Point Theory and Applications, vol. 2011, article 71, 2011.

[16] T. Abdeljawad, E. Karapınar, and K. Taş, "Existence and uniqueness of a common fixed point on partial metric spaces," Applied Mathematics Letters, vol. 24, no. 11, pp. 1900-1904, 2011.

[17] C. D. Bari, M. Milojević, S. Radenović, and P. Vetro, "Common fixed points for self-mappings on partial metric spaces," Fixed Point Theory and Applications, vol. 2012, article 140, 2012.

[18] M. A. Alghamdi, N. Shahzad, and O. Valero, "On fixed point theory in partial metric spaces," Fixed Point Theory and Applications, vol. 2012, article 175, 2012.

[19] A. Erduran, "Common fixed point of $g$-approximative multivalued mapping in ordered partial metric space," Fixed Point Theory and Applications, vol. 2013, article 36, 2013.

[20] D. Ilić, V. Pavlović, and V. Rakočević, "Extensions of the Zamfirescu theorem to partial metric spaces," Mathematical and Computer Modelling, vol. 55, no. 3-4, pp. 801-809, 2012.

[21] F. Vetro and S. Radenović, "Nonlinear $\psi$-quasi-contractions of Ćirić-type in partial metric spaces," Applied Mathematics and Computation, vol. 219, no. 4, pp. 1594-1600, 2012.
[22] T. Abdeljawad, "Fixed points for generalized weakly contractive mappings in partial metric spaces," Mathematical and Computer Modelling, vol. 54, no. 11-12, pp. 2923-2927, 2011.

[23] R. H. Haghi, S. Rezapour, and N. Shahzad, "Be careful on partial metric fixed point results," Topology and Its Applications, vol. 160, no. 3, pp. 450-454, 2013.

[24] V. Berinde, "A common fixed point theorem for compatible quasi contractive self mappings in metric spaces," Applied Mathematics and Computation, vol. 213, no. 2, pp. 348-354, 2009. 


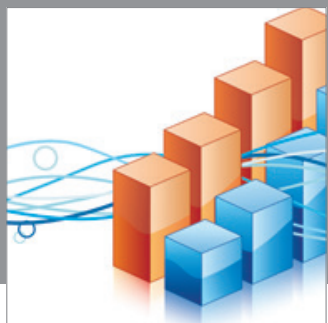

Advances in

Operations Research

mansans

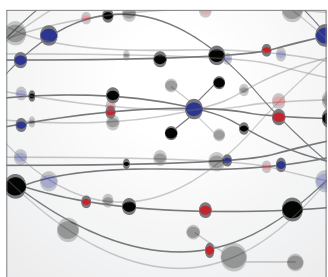

The Scientific World Journal
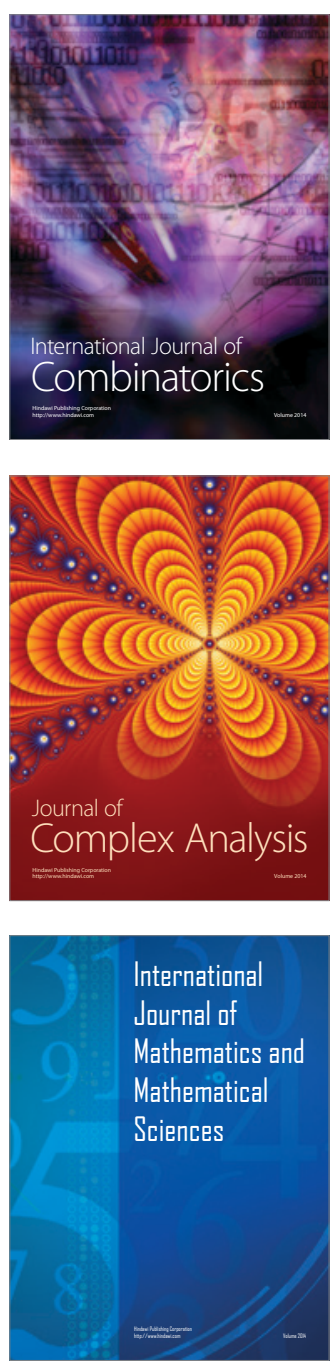
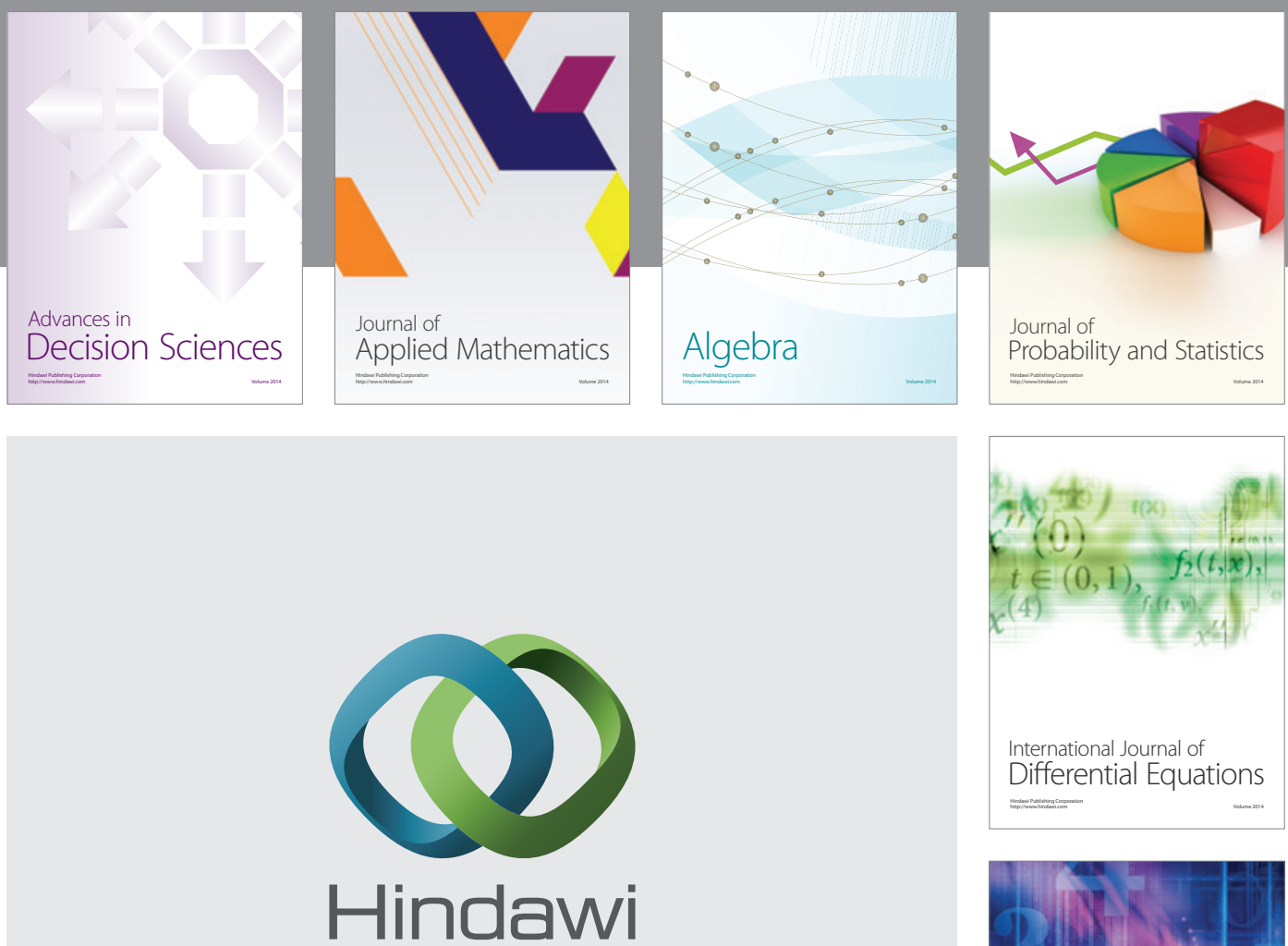

Submit your manuscripts at http://www.hindawi.com
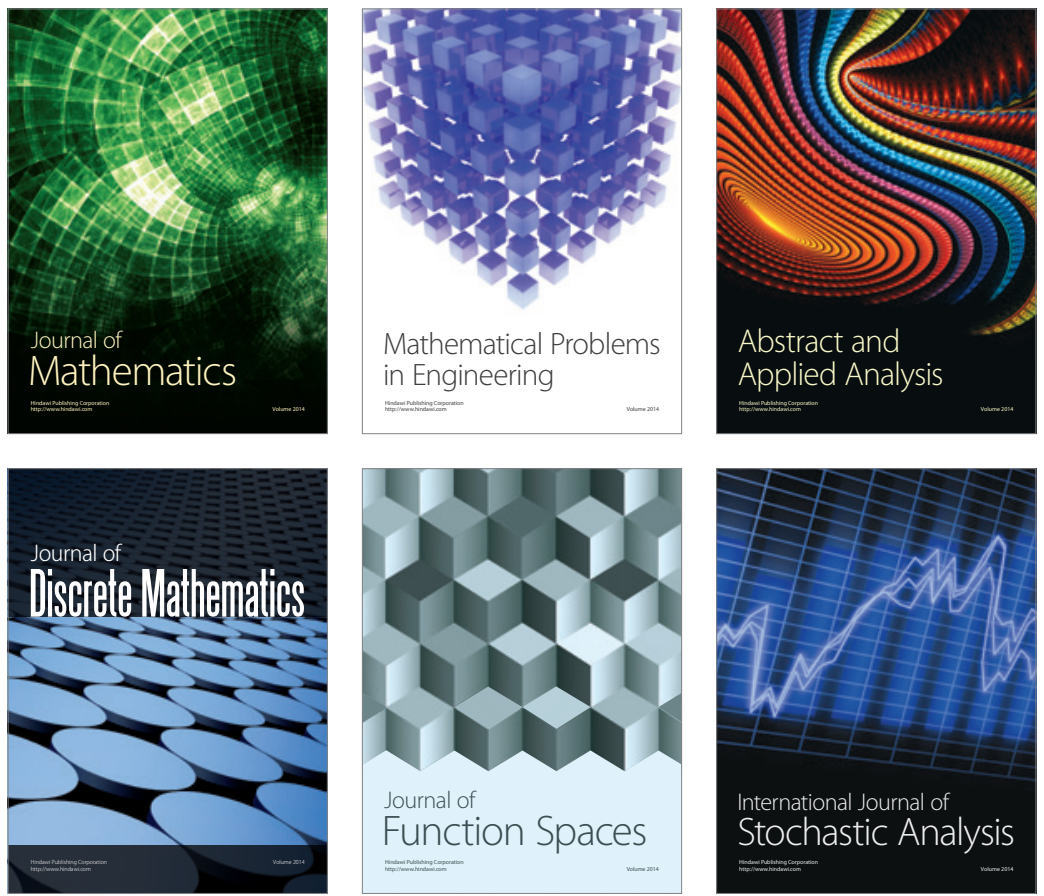

Journal of

Function Spaces

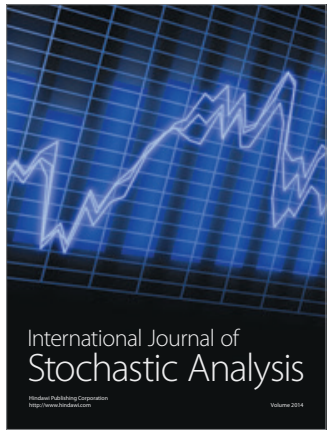

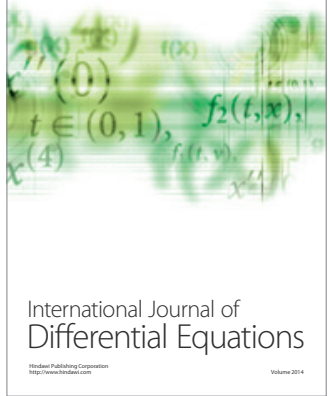
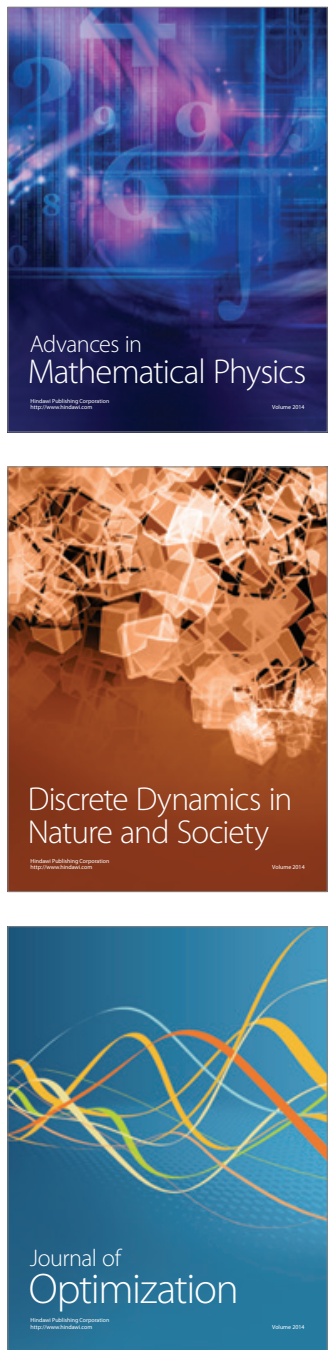